\title{
QUEEN'S
QNEIVERSITY
BELFAST
}

\section{Acceptance and commitment therapy and mindfulness for chronic pain: Model, process, and progress}

McCracken, L. M., \& Vowles, K. E. (2014). Acceptance and commitment therapy and mindfulness for chronic pain: Model, process, and progress. American psychologist, 69(2), 178-187. https://doi.org/10.1037/a0035623

\section{Published in:}

American psychologist

\section{Document Version:}

Peer reviewed version

Queen's University Belfast - Research Portal:

Link to publication record in Queen's University Belfast Research Portal

\section{Publisher rights}

(C) 2014 American Psychological Association. This work is made available online in accordance with the publisher's policies. Please refer to any applicable terms of use of the publisher.

\section{General rights}

Copyright for the publications made accessible via the Queen's University Belfast Research Portal is retained by the author(s) and / or other copyright owners and it is a condition of accessing these publications that users recognise and abide by the legal requirements associated with these rights.

Take down policy

The Research Portal is Queen's institutional repository that provides access to Queen's research output. Every effort has been made to ensure that content in the Research Portal does not infringe any person's rights, or applicable UK laws. If you discover content in the Research Portal that you believe breaches copyright or violates any law, please contact openaccess@qub.ac.uk. 
RUNNING HEAD: ACT and Mindfulness for Chronic Pain

Please cite as: McCracken, L. M., \& Vowles, K. E. (2014). Acceptance and Commitment Therapy and mindfulness for chronic pain: Model, process, and progress. American Psychologist.

Acceptance and Commitment Therapy and Mindfulness for Chronic Pain:

Model, Process, and Progress

Lance M. McCracken

King’s College London \& INPUT Pain Management Centre, Guy’s and St Thomas’ NHSFT, London, United Kingdom

Kevin E. Vowles

Department of Psychology, University of New Mexico,

United States of America

Correspondence to:

Lance M. McCracken, Ph.D.

Health Psychology Section, Psychology Department

Institute of Psychiatry

King's College London

$5^{\text {th }}$ Floor, Bermondsey Wing

Guy's Campus

London SE1 9RT

Lance.McCracken@kcl.ac.uk 


\begin{abstract}
Over 30 years ago, treatments based broadly within cognitive behavioral therapy (CBT) began a rise in prominence that eventually culminated in widespread adoption in chronic pain treatment settings. Numerous productive lines of research and treatment development were pursued in the past, and some continue today in these same veins. Just as it is designed to do the process of conducting research and analyzing evidence reveals gaps in our understanding and shortcomings in current outcomes within these approaches. A need for refinement or development seems clear. This paper reviews the progress of CBT in chronic pain and challenges now faced by researchers and clinicians working within these approaches. It then focuses in greater detail on particular developments within CBT, namely Acceptance and Commitment Therapy (ACT) and mindfulness-based approaches, as areas that may hold potential for future progress. Finally, three specific recommendations are offered to guide research the treatment development for chronic pain.
\end{abstract}




\section{Acceptance and Commitment Therapy and Mindfulness for Chronic Pain: Model, Process, and Progress}

Psychological approaches have a long history of success in the treatment of chronic pain. For the past three decades this work has been dominated by broadly cognitivebehavioral theories and methods, certainly since the first comprehensive description of these in the early 1980’s (Turk, Meichenbaum, \& Genest, 1983). Approaches to chronic pain based on Cognitive behavioral therapy (CBT) are deemed the most clinically effective and costeffective approach to chronic pain today, especially compared with commonly used medical approaches (Turk \& Burwinkle, 2005; Gatchel \& Okifuji, 2006). While CBT has had success with chronic pain, its effectiveness also has limits and could be better.

It is possibly a pivotal time in the development of CBT for chronic pain, based on a confluence of events, in the wider field of CBT and in the field of chronic pain. These events include emerging gaps in current evidence, particularly with respect to therapy process. The other events include developments in CBT theory and methods running parallel to these gaps but not yet fully applied to them. Notable among these developments are treatment approaches that contain certain radical attitudes, and depart from the logic of everyday thinking. One of these radical attitudes is that they "normalize” human suffering. They actually regard suffering as, to an extent, inherent to the human condition, as if this is how people are designed. They also question the utility of normal thinking, believing, analyzing, and problem-solving as predominant means for successfully addressing this suffering. These approaches reflect an emphasis on experiential methods rather than didactic ones, on metaphorical uses of language rather than only direct literal uses, on changing responses to symptoms rather than symptoms themselves, and on qualities in the behavior of the treatment provider. These features are reflected prominently in approaches referred to as acceptance- 
based or mindfulness-based (Hayes, Follette, Linehan, 2004), and can be called contextual cognitive behavioral therapy (CCBT; Hayes et al., 2011; McCracken, 2005).

There is a progressive quality within the approaches here labeled as CCBT, a quality that may improve the focus of further research into chronic pain and promote a next generation of treatment developments. A key strategy for improving treatment effectiveness may be to look inside these models not for better facts, ideas, or methods as such but for how the philosophies and theories contained there can provide guidance for our behavior as researchers and clinicians. We suggest that progress will not occur by getting more data alone but by organizing our efforts around specific clearly stated assumptions and goals and around a unified theoretical model. We further suggest that the philosophy, processes, and theory underlying Acceptance and Commitment Therapy (ACT), with its focus on psychological flexibility (Hayes, Strosahl, \& Wilson, 1999), may provide the guidance needed.

In this article we review the evidence-base for the broadly cognitive behavioral therapies for chronic pain. Next, we identify key challenges to the development of these methods. We then provide an overview of the ACT model as an approach to chronic pain, and examine the related area of mindfulness-based approaches. Finally, we present potential strategies for continued progress within this area.

\section{The Success of CBT for Chronic Pain}

Given that a previous article in this special issue already highlighted the prevalence of chronic pain, as well as its impacts, we will not review these issues here.

There are two core principles implicitly at the heart of cognitive behavioral approaches to chronic pain. The first is that feelings of pain and aspects of emotional, physical, and social functioning impacted by pain are both related and separable, particularly for treatment purposes. This means that problems with physical and social functioning or depression related to pain can be addressed even if the pain is not targeted directly, and even 
if it remains unchanged. The second principle is that psychological factors can influence the experience of pain itself. Approaches to chronic pain that incorporate these core principles were in their time some of the most innovative among all approaches to physical health problems within clinical psychology (Fordyce, 1976; Turk et al. 1983). Even though these core principles can continue to meet skepticism or misunderstanding from some, their spirit is now widely disseminated in current assessment and treatment methods for chronic pain.

There are at least five systematic reviews relevant to current CBT for chronic pain, each generally concluding that these approaches can produce a range of significant positive outcomes, such as reduced pain and improved daily functioning (Eccleston, Williams, \& Morley, 2009; Guzman et al., 2001; Hoffman, Papas, Chatkoff, \& Kerns, 2007; Morley, Eccleston, \& Williams, 1999; Scascighini, Toma, Dober-Spielmann, \& Sprott, 2008).

Two of the meta-analyses are particularly notable as they were done by the same group with similar methods, twice, over a period of 10 years. In 1999 this group published results from their analyses of 25 trials of cognitive and behavioral treatment for chronic pain (Morley et al., 1999). They showed that in comparison to waiting list conditions, these treatments produced significant benefits in pain, emotional functioning, coping, pain behavior, activity, and social role functioning. The median effect size was $d=.50$. In comparison to active treatment control conditions, such as pain clinic, physiotherapy, occupational therapy, or education, these treatments produced significant benefits in pain, coping, and pain behavior. The overall median effect size here was smaller, $d=.17$.

When a meta-analysis was again published by the same group 10 years later, the overall conclusion regarding cognitive and behavioral treatments for chronic pain was positive but less emphatic (Eccleston et al., 2009). This more recent review applied stricter inclusion criteria in identifying studies for analysis. They required that each trial include a psychological treatment with actual “definable psychotherapeutic content” and that each 
treatment arm had ten or more participants at the end of treatment. Their analyses of 40 trials showed that cognitive and behavioral treatments produce small effects on pain and disability and a small effect on mood particularly at follow-up.

The more recent systematic review also included assessments of the quality of treatment and of research design, allowing an examination of trends over time. These data showed that the quality of research design significantly positively correlated with the publication year of the study (rho $=.45$ ) but the quality of treatment did not (rho $=-.07$ ). The authors concluded overall that the evidence for cognitive and behavioral treatments for chronic pain is "weak," and that the quality of treatments, or the reporting of these treatments, apparently is not improving over time (Eccleston et al., 2009).

\section{Challenges in CBT for Chronic Pain}

The ultimate challenge in psychological treatment development is to find highly effective treatments that produce clinically meaningful benefits specifically linked to the psychological processes hypothesized within the treatment model (Kazdin, 2007). This is no less the goal for chronic pain treatment than in any other area of clinical psychology (Jensen, 2011; Morley \& Keefe, 2007). This is not merely a theoretical concern - it is practically important. When one can identify processes of change that are both sufficient and necessary for the benefits observed in treatment, and identify the methods that impact these processes, then one is able to optimize treatment impact. Stated more simply, processes, as the proximal link that ties method to outcome, can directly guide method choice and method development.

Rather than following processes, methods could follow fads, commonsense, or therapist emotional reactions, or beliefs (Waller, 2009). Unfortunately emotional reactions and commonsense are often compelling but misleading (Schulte \& Eifert, 2002). And sometimes both professional and patient beliefs better reflect the roots of the problem rather than the solution to the problem. If it is the case that the quality of CBT for chronic pain is 
not improving and that effect sizes are not getting larger over time, but are getting smaller, it may be that connecting methods with specific processes of change in therapy is a way to reverse these trends.

Interest in treatment processes within CBT in general appears to be increasing (David \& Montgomery, 2011; Kazdin, 2007; Murphy, Cooper, Hollon, \& Fairburn, 2009; Stice, Rohde, Seely, \& Gau, 2010). And, at this relatively early stage, data appear to be especially useful. Ironically this is because they are murkier than one might expect, and not always consistent with the traditional assumptions. In contrast to the traditional framework of CBT, and contrary to commonsense, we may not need to think or believe different thoughts or beliefs to change our behavior or to recover from the effects of psychological problems. There is, in fact, an accumulating rate of failure to find evidence that confronting negative automatic thoughts or changing the content of thoughts is necessary to affect improvements in CBT for such conditions as depression and anxiety disorders (Burns \& Spangler, 2001; Dimidjian et al., 2006; Garratt, Ingram, Rand, \& Sawalani, 2007; Jarrett, Vittengl, Doyle, \& Clarke, 2007; Longmore \& Worrell, 2007; Stice et al., 2010). Further, sometimes trying to adopt positive thinking patterns, such as about oneself, may have the opposite to the intended effect, and may lower mood and self-esteem, or may be effective only for some and not for others (Wood, Perunovic, \& Lee, 2009; see also Haeffel, 2010). This is not to say that methods directed at changing the content of thoughts or beliefs are in all cases either inert or harmful. This is simply to say that the evidence does not say they are necessary for treatment success, and it appears some methods are not risk-free.

Within CBT for chronic pain, there is similarly a lack of clarity in treatment processes. From a traditional CBT perspective, an assumed mechanism of treatment is change in the content of cognitions related to pain, depression, or anxiety, including constructs such as catastrophizing, hopelessness, helplessness, and perceived control (Jensen, 2011; Morley 
\& Keefe, 2007). Measures of pain-related cognitions of one type or another clearly correlate with measures of current functioning, and changes in some of these cognitions clearly correlate with improvements in functioning observed during treatment (e.g., Burns, Johnson et al., 2003; Jensen, Turner, Romano, 2001; Jensen, Turner, \& Romano, 2007; Woby, Watson, Roach, \& Urmston, 2004). However, this is not the complete story. First, it is not clear that methods aimed at changing cognitive content related to pain are specifically necessary for changes in these cognitions. It appears these can change even when cognitive change methods are not a part of treatment (Smeets, Vlaeyen, Kester, \& Knottnerus, 2006; Vowles, McCracken, \& Eccleston, 2007). Further, exaggerated negative thoughts about pain can be successfully induced but doing so does not necessarily increase perceptions of pain or decrease pain tolerance (Severeijns, van den Hout, \& Vlaeyen, 2005). Finally, attempts to achieve change in cognitive content sometimes, paradoxically, increase the severity of pain (Goubert et al., 2004; Masedo \& Esteve, 2007; Sullivan, Rouse, Bishop, \& Johnston, 1997). Hence, from a number of perspectives, methods to target the content of thoughts and beliefs about pain may not be critical to chronic pain treatment, and, as we say, the necessity of content change remains somewhat unclear.

Another presumed mechanism of treatment effect in CBT for chronic pain derives from a model of coping skills training, adherence, and maintenance (Turk et al., 1983). According to this model, for those disabled and distressed by chronic pain, the experience represents a stressor that overwhelms coping abilities. It follows that when those who are thus overwhelmed are able to learn, and consistently use, more effective coping strategies their distress will be reduced and their functioning improved. This model is entirely logical.

In one study that investigated the model of skills training and adherence, a group of 2,345 patients completing a multidisciplinary course of CBT were assessed after treatment and at follow-up for their adherence to traditional CBT skills, including stretching and 
physical exercise, activity pacing, and “methods for challenging and changing unhelpful thoughts” (Curran, Williams, \& Potts, 2009). In subsequent multivariate analyses, adherence to skills use was a significant mediator between post treatment and follow-up outcomes. However, the variances accounted for was small, just 3.0\%, which led the authors to question the role of adherence to these skills in relation to treatment outcome. Results such as these are not unique. In another study of 114 people with chronic pain completing a multidisciplinary version of CBT based on ACT, more or less the same traditional skills were assessed following treatment (Vowles \& McCracken, 2010). It was found that the use of these skills did indeed increase significantly during treatment. However, this increase was unrelated to improvements in any of the outcome measures at follow-up. Both of these studies failed to provide support for the necessity of the skills trained in traditional CBT for chronic pain. In fact, they suggest that when skills training is done there must be other processes changing at the same time, processes that are possibly not explicitly targeted.

Failure to adequately investigate and clarify processes in treatment may lead to confusion over choice of methods, and possibly an overly inclusive approach, where patients get a little bit of everything. In turn this may slow the development of methods.

The methods used within CBT in the 1980’s included training in skills for managing moods, attention, thoughts, and activity, including relaxation, physical exercise, and techniques for altering negative thoughts and beliefs and increasing positive ones, exposurebased methods, goal-setting, and the like. Certainly most researchers and clinicians have noticed that, with one or two exceptions, the methods being used in most centers following a CBT model today are fundamentally the same as they were more than 25 years ago.

\section{ACT for Chronic Pain: Model, Process, and Evidence}

ACT is a treatment approach that emerges squarely within the family of CBT. It is designed to be applicable to a broad range of psychological problems. It has roots in learning 
theory and in laboratory studies of basic behavioral processes. It also extends this tradition with laboratory research into processes of language and cognition guided by what is called Relational Frame Theory (Hayes, Barnes-Holmes, \& Roche, 2001). ACT includes a combination of acceptance and mindfulness methods along with activation and behavior change methods. It includes an emphasis on the role of cognitive processes and emotional experiences in relation to behavior change, just as in most approaches within CBT (Hayes et al., 1999).

ACT can be distinguished from other approaches within CBT in the philosophical assumptions and the scientific strategies it adopts. ACT adopts a pragmatic approach to knowledge, as opposed to one that relies on correspondence with reality. Here "pragmatic" means successfully reaching the goals of the analyses. The approach to psychological events in ACT is specifically functional and contextual, placing the emphasis on whether these events can be observed to have a relationship of influence with a particular behavior pattern and whether they are potentially manipulable by psychological methods. Thoughts or feelings are not deemed helpful or unhelpful from their form, frequency, or appearance, from what they say or whether they feel uncomfortable, for example. It is this core functional contextual framework that allows within ACT more routes toward healthy functioning, one where methods can seek to reduce psychological experiences such as pain, fear, or sadness, if this achieves improved functioning, and another where methods seek to reduce the influence these experiences exert over behavior. Along this second route to healthy functioning the experiences may remain, may increase, or may decrease, and this is not the primary focus.

Within ACT a set of broadly applicable and integrative treatment processes is proposed, the core being psychological flexibility. Psychological flexibility is the capacity to continue with or change behavior, in a manner that is guided by one's goals, and in a context of interacting cognitive and direct non-cognitive influences. Here there is an important 
distinction between two sets of influences on behavior, those that are based in cognitive processes and those that are not. Simply put, there are influences that arise from thinking, judging, analyzing, "information processing," or the mind, and there are influences that arise from direct sensory contact with the world. These influences are in a constant process of interacting and combining in the coordination of behavior. The one hitch is that the cognitivebased influences can readily dominate, without a person being aware this is happening, and this can lend behavior an ineffective quality. Psychological inflexibility, then, is based in this particular quality of behavior being dominated by cognitively-based influences and being insulated from other sources of influence.

The processes behind psychological flexibility present a model for how thoughts, beliefs, rules, and instructions, as well as pain or other psychological experiences, can narrow the range of an individual's available responses and present obstacles to healthy behavior and behavior change. Psychological flexibility includes a set of subprocesses: acceptance, cognitive defusion, flexible attention to the present, self-as-observer, values-based action, and committed action (Hayes et al. 1999), more succinctly summarized as behavior that is open, aware, and active (Hayes et al., 2011) or open, centered, and engaged (Hayes et al., 2012).

As mentioned, psychological flexibility is an inherently integrative process. The component process of cognitive defusion, for example, yields methods that address problems based in cognitive processes, thoughts, and beliefs no matter the content, whether they are blaming, catastrophic, defeated, discouraged, fearful, helpless, hopeless, or self-critical. Cognitive defusion methods aim to reduce the dominance and impact of this content without necessarily changing the content itself. The component process of acceptance, another example of an integrative process, yields methods to address feelings, whether these feelings include anger, anxiety, depression, fear, guilt, pain, shame, and so on. Acceptance methods aim to help behavior to have a quality of engaging, including moments when that engaging is 
associated with unwanted feelings, and refraining, particularly refraining from attempts to control feelings. From a functional contextual framework, cognitive defusion and acceptance are not viewed as positive process that must be done all of the time; they are merely useful when they serve better functioning.

There is some debate as to whether ACT includes anything new or may simply represent some relabeling or superficial redesign of already existing methods (Hofmann \& Asmundson, 2008). Certainly, ACT adopts familiar widely used methods such as exposure, behavioral activation, skills training, mindfulness, and methods for building a close and intensive therapeutic relationship, for example. It does this consciously and transparently.

There do appear to be discriminable distinctions in the current practice of CBT. Brown, Gaudiano, and Miller (2011) conducted an online survey of 176 licensed, practicing, cognitive-behavioral therapists and 88 identified themselves as either traditional cognitivebehavioral or acceptance-based. Results showed that these two groups were similar in most respects assessed, such as in attitudes toward evidence-based practice and in thinking style. The primary difference between the groups was the treatment techniques they use. Those self-described as acceptance-based in orientation reported greater use of exposure, mindfulness, and family systems techniques, and they reported using a wider range of total techniques. Those self-described as having a traditional CBT orientation reported greater use of cognitive restructuring and relaxation. So, data like these demonstrate that there are observable differences in current practices whether one wants to call it one thing or another. The evidence-base for ACT has grown rapidly in recent years, including several systematic reviews focused on a mix of disorders and generally showing medium-sized average effect sizes (Öst, 2008; Powers, Zum Vörde Sive Vörding, \& Emmelkamp, 2009; Ruiz, 2010; see also Gaudiano, 2011). In each of these reviews it was generally concluded that ACT is neither inferior nor superior in efficacy compared to current established 
approaches. Given that many of the ACT trials included in these meta-analyses were preliminary or pilot trials, conducted as doctoral dissertation projects, run with little funding, and so forth, it seems promising that they compare relatively favorably with more established and refined trials of traditional CBT (e.g., Gaudiano, 2009).

There are now at least five RCTs related to ACT for chronic pain, each one yielding positive support (Dahl, Wilson, Nilsson, 2004; Johnston, Foster, Shennan, Starkey, \& Johnson, 2010; Thorsell, Finnes, Dahl, Lundgren, Gybrant, Gordh, \& Buhrman, 2011; Wetherell et al., 2011; Wicksell, Ahlqvist, Bring, Melin, \& Olsson, 2008). Additional support for ACT as applied to chronic pain comes from a number of partially controlled trials (e.g., McCracken, Vowles, \& Eccleston, 2005; Vowles, Wetherell, \& Sorrell, 2009), a series of relatively large scale effectiveness studies (e.g.,Vowles \& McCracken, 2008; McCracken \& Gutiérrez-Martínez, 2011) producing average effect sizes across outcome domains in the large range, $d=.85$ to .89 , and an effectiveness trial with follow-up data at three-years post treatment (Vowles, McCracken, \& Zhao-O’Brien, 2011) with an average effect size in the medium range, $d=.57$. Notably, consistent positive effects of ACT include increased physical and social functioning and decreased pain-related medical visits, even three years following treatment. ACT is listed by the APA Division of Clinical Psychology as an empirically supported treatment with “strong research support” for general chronic pain (Society of Clinical Psychology, 2011). A meta-analysis of studies of acceptance and mindfulness-based treatments for chronic pain $(\mathrm{N}=22)$ concluded that these approaches appear at least equally effective compared to traditional CBT (Veehof et al., 2011).

Most of the ACT trials for chronic pain have investigated treatment process to some extent or other. Results from these analyses show that increases in acceptance of pain correlate with improvements during treatment in anxiety, depression, and disability (McCracken et al., 2005; Vowles \& McCracken, 2008) and also that increases in values- 
based action correlate with improvement observed at a three-month follow-up in the same outcomes (Vowles \& McCracken, 2008). In a more comprehensive study of process, increases in combined measures of acceptance of pain, general psychological acceptance, mindfulness, and values-based action during the active phase of treatment significantly correlated with improvements in anxiety, depression, and disability, at a three-month followup, independent of changes in pain (McCracken \& Gutiérrez-Martínez, 2011).

Wicksell, Olsson, and Hayes (2010) explored processes of change in a trial of ACT for chronic pain, using a more sophisticated, formal, statistical test of mediation, and looking particularly at outcomes for life satisfaction and pain-related disability. In their results they found that psychological flexibility significantly mediated these outcomes, as predicted. Pain, emotional distress, fear of movement, and self-efficacy did not. Findings here support the notion that ACT produces significant improvements in outcome for people with chronic pain and, when it does this, these improvements are specifically mediated by the therapeutic process specified in the underlying theory, and not by processes specified in other theories.

\section{Mindfulness: Method, Process, and Outcome}

Mindfulness-based methods are deemed effective for conditions like chronic pain, both in terms of symptom reduction and improved emotional functioning (Baer, 2003; Grossman, Niemann, Schmidt, \& Walach, 2004). At the same time there may be opportunities for development and for greater integration between ACT and mindfulnessbased approaches.

One area for development in mindfulness studies is the examination of treatment process. Given the relatively large number of outcome studies of mindfulness-based approaches for chronic pain, there have been surprisingly few directly addressing mindfulness per se as a process of change, and even fewer that have attempted to separate component process within mindfulness. In a study of 174 participants who received a 
Mindfulness-Based Stress Reduction intervention (MBSR; Kabat-Zinn, 1990) for problems with stress, chronic pain, or anxiety, time spent in home practice of mindfulness correlated with improvements in particular facets of mindfulness and with improvements in psychological well-being, stress, and psychological symptoms (Carmody \& Baer, 2008). A similar result was demonstrated in another study of MBSR specifically focused on treatment for chronic pain (Rosenzweig et al., 2010). Here they showed a relationship between home practice and improvements in psychological distress, somatization, and ratings of general health. Nonetheless, neither of these studies shows a specific causal role for facets of mindfulness processes or methods and, even so, studies like these are relatively rare.

The limited data linking specific mindfulness-related processes to improvements in outcomes leaves researchers and clinicians with the conclusion that mindfulness methods are beneficial for health and functioning in people with chronic pain and without knowing how these benefits are achieved. Where there have been attempts to identify specific processes within mindfulness, the very interesting processes identified, such as re-perceiving, decentering, and intimate detachment (Shapiro, Carlson, Astin, \& Freedman, 2006), do not seem to achieve a quality of greater precision or direct manipulablability compared to mindfulness itself. They also do not link with a theoretical framework or a comprehensive set of behavior change principles.

Another area for further development in studies of mindfulness-based treatment methods for chronic pain is on outcome. Most previous studies have focused on mental health outcomes, such as symptoms of anxiety and depression, and only a small number on activity related outcomes, such as physical activity and social role performance (Bohlmeijer et al., 2010; Keng, Smoski, \& Robins, 2011; Chiesa \& Serretti, 2011). As a result there is a relative lack of evidence to show that mindfulness-based approaches can change behavior patterns in ways that translate into improved physical and social functioning. Certainly 
existing evidence for such changes in people with chronic pain could be strengthened (e.g,. Astin et al., 2003; Schmidt et al., 2011; Morone, Greco, \& Weiner, 2008).

It may enhance the overall effect of mindfulness methods, and help produce results of greater practical importance, to combine these methods with methods that more directly aim to improve engagement in wider patterns of daily activity. There are examples of treatment approaches that do this. One of these is Dialectical Behavior Therapy (DBT; Linehan, 1993). As far as we know there are no controlled trials of DBT for chronic pain, even though the methods appears appropriate and feasible (Linton, 2010). The other approach that blends mindfulness-related processes and direct behavior change methods is ACT.

\section{Suggestions for Progress}

Continuing development of psychological treatments for chronic pain is like a journey, a journey that requires directions or guidance. One source of guidance emerges from evidence from basic and applied research, but guidance cannot come from evidence alone. Even the process of obtaining evidence requires guidance. Research questions typically require a theoretical foundation so that they are systematic and organized, so that one development leads to the next, and so that one does not keep walking over the same old ground. We highlight three strategic choices here that might facilitate the development of CBT for chronic pain. We suggest that researchers and clinicians interested in chronic pain (a) let go of unproductive ideas, (b) adopt a clear scientific philosophy, and (c) develop treatment methods linked to treatment processes and a unified theoretical model.

Letting Go. One of the potential problems with clinical psychology is that the activities of researchers and clinicians are themselves part of the subject matter they are studying and treating (Hayes, 2005; Vilardaga, Hayes, Levin, \& Muto, 2009). There are many possible influences on choices made for research questions, key variables of interest, theories adopted, and methods used, and some of these offer little potential for development. 
This is not a new idea, outdated, discredited, and unproductive ideas and practices often continue within Psychology even when they are known by experts to be of little value (Norcross, Koocher, and \& Garofalo, 2006). The greater problem though is the many approaches that are not obviously “psychoquakery,” as these authors recently called it. This includes particularly approaches that provided an advance in research or treatment in the past but have perhaps outlived their usefulness.

There are a number of key concepts in CBT for chronic pain that were pivotal in their time. These concepts include coping, self-management, and self-efficacy, among others. To a degree these concepts are commonsense. If one has great difficulties, one needs to learn to cope more effectively. If doctors cannot help, one must learn to manage without them. If one is discouraged in reaching goals, one ought to think confidently. These concepts have enjoyed great popularity and persistence, likely due to their strong intuitive appeal. At the same time, we humbly suggest, they have stopped promoting progress. Each tends to frame the problem of chronic pain too narrowly, particularly if they are followed exclusively. They are missing coherent links with active programs of applied and basic research and, most importantly, they are not producing new treatment methods. As we say, they have become unproductive.

Psychological flexibility is not commonsense. It includes complex processes in the interaction of verbal and non-verbal influences on the coordination of behavior. It is linked to active programs of basic and applied research. Here it is not just what we think or feel that matters but the historical and situational context around what we think and feel. This added layer of analysis seems more consistent with the complexity of human behavior problems.

Philosophy of science and scientific strategy. Scientific activity can be disorganized and inefficient unless it is guided by carefully chosen and stated goals, definitions of terms, and philosophical assumptions. For example the philosophy behind ACT, as mentioned 
earlier, is functional contextualism. ACT is not primarily defined as a set of techniques but by its adherence to this philosophy and its focus on enhancing psychological flexibility (Hayes et al., 2012). This philosophy defines the subject matter, model of causality, and epistemological assumptions that one would follow in building a knowledge base around this approach. These, in turn, have direct implications for the behavior of the researcher and clinician. For example, the goal of functional contextualism is to create a comprehensive scientific account of behavior that allows prediction and influence (Hayes, 1993). Behavior here is explicitly defined as the activity of the whole organism defined in a situational and historical context. Its methods are inductive. Its truth criterion is successful goal achievement.

From each of the philosophical assumptions of ACT actions are clear: the dependent variable is always behavior in context, potential processes for study are abstracted from patterns of observed behavior, the independent variables within its analyses must be manipulable in principle to meet the goal of influence, and the analyses proceeds until the goals of the analyses are achieved, that being the capacity to influence the events under investigation. The abstracted principles thus supported are then built into a wider comprehensive account with the aim that it achieves precision, scope, and depth, in other words, specific in its application, wide in the range of psychological problems to which it applies, and consistent with other levels of analysis, such as biology, neurology, physics, and so forth (Hayes et al., 2012; Vilardaga et al., 2009).

Linking method, process, and a unified theoretical model. There is "nothing so practical as a good theory” are the oft-quoted words of Kurt Lewin (1952). This statement is not an advertisement for the generic goodness of "theory" but for the practical value of "good” theory. The practical part of a good theory lies in its ability to integrate and organize observations, so that the behavior of researchers and clinicians might be integrated and 
organized with them, and importantly, to remain open to updating as new findings emerge (Hayes, 2005; Vilardaga et al., 2009).

It is quite difficult to pin down the theory or theories behind current psychological treatments for chronic pain, including CBT, and this leads to several problems. There are many different treatments, some are based on theoretical models and some are not, and the current view is that no one model seems to explain most of these (Jensen, 2011). It has been argued that if no one theoretical model encompasses all treatments, and if each treatment only targets finite subsets of psychological factors, then any choice of theory will exclude some of these factors and could result in suboptimal treatment for some patients (Jensen, 2011). In fact, sometimes different treatments with distinctly different theoretical frameworks are combined within the same treatment packages in an attempt to be comprehensive (Eccelston et al., 2009), and this creates its own problems. A risk in this bewildering situation, in addition to the possibility of suboptimal treatment, is that researchers and clinicians will either dismiss the importance of theory out of frustration, or simply follow no particular theory. In either case their behavior becomes disorganized.

Just as there is an ever growing number of new psychological treatments for chronic pain, so too there is an ever growing number of new psychological variables and related data. Mature theories, however, provide a basis for integrating current findings into a smaller number of broader principles (Hayes, 2005). As mentioned, evidence alone is not enough to progress a field, just as science is not merely the accumulation of facts. It is better if facts are organized and cohere around a finite number of core principles. This is practical.

An example of a relatively broad and integrating process is experiential avoidance. Experiential avoidance refers to the range of actions one takes when unwilling to have contact with psychological experiences and thus acts to escape or avoid them, a key process of psychological inflexibility (Hayes, Wilson, Strosahl, Gifford, \& Follette, 1996). 
Experiential avoidance appears to be a key dimension of psychopathology in a wide range of behavior problems, including anxiety, depression, substance abuse, suicide, borderline personality disorder, effects of trauma and sexual abuse, and chronic pain, among others. Experiential avoidance may help explain such things as failures in chronic pain treatment, such as in relaxation methods, distraction, rest, and pacing strategies (e.g., Cioffi \& Holloway, 1993; Goubert et al., 2004; McCracken \& Samuel, 2007; Karsdorp \& Vlaeyen, 2009). The therapeutic counterpart to experiential avoidance is acceptance, another highly integrative process.

Despite the constant generation of new variables within studies of chronic pain, most including various thinking patterns or beliefs, it seems none of these have yet led to a single new treatment strategy or method. On the other hand, as far as we can identify, there has not been a single new process or variable generated within ACT since its six-part model was first outlined, in the mid 1990's. And, yet where ACT is economical in the generation of new variables it is relatively prolific in generating a wide range of new methods or in consciously incorporating old ones (Brown et al., 2011). It is also prolific in applying itself to increasingly diverse behavior problems, some would say disproportionately so given its relatively recent appearance. It has been documented that in just three selected journals, Journal of Consulting and Clinical Psychology, Behaviour Research and Therapy, and Behavior Therapy, in the years since the publication of the first book on ACT, there have been RCT results published addressing at least 18 different psychological problem areas, including psychosis, diabetes, chronic pain, work stress, depression, substance abuse, smoking, trichotillomania, prejudice and stigma of several kinds, and obsessive-compulsive disorder, among others (Hayes et al., 2012).

\section{Conclusions}


Traditional CBT for chronic pain has been very successful in many ways. It is familiar to patients, treatment providers, and funding bodies. It is widely regarded as effective, and its key concepts are a part of the established discourse on chronic pain. On the other hand, if we measure the success of traditional CBT for chronic pain according to the rate at which it has produced new and more effective treatment methods, a distinctly different picture emerges where success has been more modest.

Our overarching purpose here was to identify a potential pathway for progress for psychological treatments for chronic pain. It is appropriate that this process both actively recognize the successes of the past and embrace the areas where progress is insufficient. These areas particularly include the identification of therapy process and, perhaps more importantly, the explicit linking of theoretical assumptions, therapy processes, and clinical technique. Buoyed by early success in chronic pain CBT may have become firm on method and loose on process. We advocate reversing this so that research and treatment development are more firm on process and loose on method. In presenting ACT as a potential route toward progress, this is not so much a call for a shift in treatment techniques but more a shift in the process of development.

We suggested a three step process of development: (a) let go of variables and processes that have ceased to be useful guides for research and treatment development, (b) choose scientific goals and philosophical assumptions, and (c) begin treatment development guided by process and theory. The matter of choosing goals and philosophical assumptions may be a subtle one. A difference may be as small as a shift from seeking to understand the reality of the world toward seeking ways to act successfully in the world. In any case the three part recommendation is not miles away from Accept, Choose, and Take action. 


\section{References}

Astin, J. A., Berman, B. M., Bausell, B., Lee, W., \& Hochberg, M. (2003). The efficacy of mindfulness meditation plus qigong movement therapy in the treatment of fibromyalgia: A randomized controlled trial. The Journal of Rheumatology, 30, 22572262.

Baer, R. A. (2003). Mindfulness training as a clinical intervention: A conceptual and empirical review. Clinical Psychology: Science and Practice, 10, 125-143.

Bailey, K. M., Carleton, R. N., Vlaeyen, J. W. S., \& Asmundson, G. J. G. (2010). Treatments addressing pain-related fear and anxiety in patients with chronic musculoskeletal pain: A preliminary review. Cognitive Behavioural Therapy, 39, 46-63.

Bohlmeijer, E., Prenger, R., Tall, E., \& Cuijpers, P. (2010). The effects of mindfulness-based stress reduction therapy on mental health of adults with a chronic medical disease: A meta-analysis. Journal of Psychosomatic Research, 68, 539-544.

Brown, L. A., Gaudiano, B. A., Miller, I. W. (2011). Investigating the similarities and differences between practicioners of second- and third-wave cognitive-behavioral therapies. Behavior Modification, 35, 187-200.

Burns, D. D., \& Spangler, D. L (2001). Do changes in dysfunctional attitudes mediate changes in depression and anxiety in cognitive behavioral therapy? Behavior Therapy, 32, 337-369.

Burns, J. W., Kubilus, A., Bruehl, S., \& Harden, R. N. (2003). Do changes in cognitive factors influence outcome following multidisciplinary treatment for chronic pain? Journal of Consulting and Clinical Psychology, 66, 434-439.

Cheisa, A., \& Serretti, A. (2011). Mindfulness-based interventions for chronic pain: A systematic review. The Journal of Alternative and Complementary Medicine, 17, 8393. 
Carmody, J., \& Baer, R. A. (2008). Relationships between mindfulness practice and levels of mindfulness, medical and psychological symptoms and well-being in a mindfulnessbased stress reduction program. Journal of Behavioral Medicine, 31, 23-33.

Curran, C., Williams, A. C. de C., Potts, H. W. W. (2009). Cognitive-behavioral therapy for persistent pain: Does adherence after treatment affect outcome? European Journal of Pain, 13, 178-188.

Dahl, J., Wilson, K. G., Nilsson, A. (2004). Acceptance and Commitment Therapy and the treatment of persons at risk for long-term disability resulting from stress and pain symptoms: A preliminary randomized trial. Behavior Therapy, 35, 785-801.

David, D., \& Montgomery, G. H. (2011). The scientific status of psychotherapies: A new evaluative framework for evidence-based psychosocial interventions. Clinical Psychology Science and Practice, 18, 89-99.

Dimidjian, S., Hollon, S. D., Dobson, K. S., Schmaling, K. B., Kohlenberg, R. J., Addis, M. E., Gallop, R., McGlinchey, J. B., Markley, D. K., Gollan, J. K., Atkins, D. C., Dunner, D. L., Jacobson, N. S. (2006). Randomized trial of behavioral activation, cognitive therapy, and antidepressant medication in the acute treatment of adults with major depression. Journal of Consulting and Clinical Psychology, 74, 658-670.

Eccleston, C., Williams, A. C., \& Morley S. (2009). Psychological therapies for the management of chronic pain (excluding headache) in adults (Review). Cochrane Database of Systematic Reviews, Issue 2. Art. No.:CD007407. DOI: 10.1002/14651858.CD007407.pub2.

Garratt, G., Ingram, R. E., Rand, K. L., \& Sawalani, G. (2007). Cognitive processes in cognitive therapy: Evaluation of the mechanisms of change in the treatment of depression. Clinical Psychology: Science and Practice, 14, 224-239.

Gatchel, R. J., \& Okifuji, A. (2006). Evidence-based scientific data documenting the 
treatment and cost-effectiveness of comprehensive pain programs for chronic nonmalignant pain. The Journal of Pain, 7, 779-793.

Goubert, L., Crombez, G., Eccleston, C., \& Devulder, J. (2004). Distraction from chronic pain during a pain-inducing activity is associated with greater post-activity pain. Pain, 110, 220-227.

Grossman, P., Niemann, L., Schmidt, S., Walach, H. (2004). Mindfulness-based stress reduction and health benefits: A meta-analysis. Journal of Psychosomatic Research, $57,35-43$.

Guzmán, J., Esmail, R., Karjalainen, K., Malmivaara, A., Irvin, E., Bombardier, C. (2001). Multidisciplinary rehabilitation for chronic low back pain: Systematic review. BMJ, 322, 1511-1516.

Haeffel, G. J. (2010). When self-help is no help: Traditional cognitive skills training does not prevent depressive symptoms in people who ruminate. Behaviour Research and Therapy, 48, 152-157.

Hayes, S. C. (2005). Eleven rules for a more successful clinical psychology. Journal of Clinical Psychology, 61, 1055-1060.

Hayes, S. C., Barnes-Holmes, D., \& Roche, B. (2001). Relational frame theory: A postSkinnerian account of human language and cognition. New York: Kluwer Academic/Plenum Publishers.

Hayes, S. C., Follette, V. M., \& Linehan, M. M. (2004). Mindfulness and acceptance : Expanding the cognitive-behavioral tradition. New York: The Guilford Press, 2004.

Hayes, S. C., Strosahl, K., Wilson, K. G. (1999). Acceptance and Commitment Therapy: An experiential approach to behavior change. New York: Guilford Press.

Hayes, S. C., Strosahl, K. D., \& Wilson, K. G. (2012). Acceptance and Commitment Therapy: The process and practice of mindful change. New York: The Guildford Press. 
Hayes, S. C., Villatte, M., Levin, M., \& Hildebrandt, M. (2011). Open, aware, and active: contextual approaches as an emerging trend in the behavioral and cognitive therapies. Annual Review of Clinical Psychology, 7, 141-168.

Hayes, S. C., Wilson, K. G., Strosahl, K., Gifford, E. V., \& Follette, V. M. (1996). Experiential avoidance and behavioral disorders: A functional dimensional approach to diagnosis and treatment. Journal of Consulting and Clinical Psychology, 64, 11521168.

Hoffman, B. M., Papas, R. K., Chatkoff, D. K., Kerns, R. D. (2007). Meta-analysis of psychological interventions for chronic low back pain. Health Psychology, 26, 1-9.

Hofmann, S. G., \& Asmundson, G. J. (2008). Acceptance and mindfulness-based therapy: New wave or old hat? Clinical Psychology Review, 28, 1-16.

Jarrett, R. B., Vittengl, J. R., Doyle, K., \& Clark, L. A. (2007). Changes in cognitive content during and following cognitive therapy for recurrent depression: Substantial and enduring, but not predictive of change in depressive symptoms. Journal of Consulting and Clinical Psychology, 75, 432-446.

Jensen, M. P. (2011). Psychosocial approaches to pain management: An organizational framework. Pain, 152, 717-725.

Jensen, M. P., Turner, J. A., \& Romano, J. M. (2007). Changes after multidisciplinary pain treatment in patients pain beliefs and coping are associated with concurrent changes in patient functioning. Pain, 131, 38-47.

Kabat-Zinn, J. (1990). Full catastrophe living: Using the wisdom of your body and mind to face stress, pain, and illness. New York: Dell.

Karsdorp, P. A., \& Vlaeyen, J. W. S. (2009). Active avoidance but not activity pacing is associated with disability in fibromyalgia. Pain, 147, 29-35.

Kazdin, A. E. (2007). Mediators and mechanisms of change in psychotherapy research. 
Annual Review of Clinical Psychology, 3, 1-27.

Keng, S., Smoski, M. J., \& Robins, C. J. (2011). Effects of mindfulness on psychological health: A review of empirical studies. Clinical Psychology Review, 31, 1041-1056.

Kindermans, H. P. J., Roelofs, J., Goossens, M. E. J. B., Huijnen, I. P. J., Verbunt, J. A., \& Vlaeyen, J. W. S. (2011). Activity patterns in chronic pain: Underlying dimensions and associations with disability and depressed mood. Journal of Pain, 12, 1049-1058.

Lewin, K. (1952). Field theory in social science: Selected theoretical papers by Kurt Lewin. London: Tavistock.

Linehan, M. M. (2011). Cognitive-Behavioral Treatment of borderline personality disorder. New York: The Guilford Press.

Linton, S. J. (2010). Applying Dialectical Behavior Therapy to chronic pain: A case study. Scandinavian Journal of Pain, 1, 50-54.

Masedo, A. I, \& Esteve, M. R. (2007). Effects of suppression, acceptance and spontaneous coping on pain tolerance, pain intensity and distress. Behaviour Research and Therapy, 45, 199-209.

McCracken, L. M. (2005). Contextual cognitive-behavioral therapy for chronic pain. Seattle: IASP Press.

McCracken, L. M., \& Gutiérrez-Martínez, O. (2011). Processes of change in psychological flexibility in an interdisciplinary group-based treatment for chronic pain based on Acceptance and Commitment Therapy. Behaviour Research and Therapy, 49, 267274.

McCracken, L. M., \& Samuel, V. M. (2007). The role of avoidance, pacing, and other activity patterns in chronic pain. Pain, 130, 119-125.

McCracken, L. M. Vowles, K. E., \& Eccleston, C. (2005). Acceptance-based treatment for persons with complex longstanding chronic pain: A preliminary analysis of treatment 
outcome in comparison to a waiting phase. Behaviour Research and Therapy, 43, 1335-1346.

Morley, S., Eccleston, C., \& Williams, A. (1999). Systematic review and meta-analysis of randomized controlled trials of cognitive behaviour therapy and behaviour therapy for chronic pain in adults, excluding headache. Pain, 80, 1-13.

Morley, S. \& Keefe, F. J. (2007). Getting a handle on process and change in CBT for chronic pain. Pain, 127, 197-198.

Morone, N. E., Greco, C. M., \& Weiner, D. K. (2008). Mindfulness meditation for the treatment of chronic low back pain in older adults: A randomized controlled pilot study. Pain, 134, 310-319.

Murphy, R., Cooper, Z., Hollon, S. D., \& Fairburn, C. G. (2009). How do psychological treatments work? Investigating mediators of change. Behaviour Research and Therapy, 47, 1-5.

Norcross, J. C., Koocher, G, P., \& Garofalo, A. (2006). Discredited psychological treatments and tests: A delphi poll. Professional Psychology: Research and Practice, 37, 515522.

Öst, L. (2008). Efficacy of the third wave of behavioral therapies: A systematic review and meta-analysis. Behaviour Research and Therapy, 46, 296-321.

Rosenzweig, S., Greeson, J. M., Reibel, D. K., Green, J. S., Jasser, S. A., Beasley, D. (2010). Mindfulness-based stress reduction for chronic pain conditions: Variations in treatment outcomes and role of home meditation practice. Journal of Psychosomatic Research, 68, 29-36.

Ruiz, F. J. (2010). A review of Acceptance and Commitment Therapy (ACT) empirical evidence: Correlational, experimental psychopathology, component and outcome studies. International Journal of Psychology and Psychological Therapy, 10, 125-162. 
Scascighini, L., Toma, V., Dober-Spielmann, S., \& Sprott, H. (2008). Multidisciplinary treatment for chronic pain: A systematic review of interventions and outcomes. Rheumatology, 47, 670-678.

Schmidt, S., Grossman, P., Schwarzer, B., Jena, S., Naumann, J., \& Walach, H. (2011). Treating fibromyalgia with mindfulness-based stress reduction: Results from a 3armed randomized controlled trial. Pain, 152, 361-369.

Schulte, D., \& Eifert, G. H. (2002). What to do when manuals fail? The dual model of psychotherapy. Clinical Psychology: Science and Practice, 9, 312-328.

Severeijns, R., van den Hout, M. A., \& Vlaeyen, J. W. S. (2005). The causal status of pain catastrophizing: An experimental test with healthy participants. European Journal of Pain, 9, 257-265.

Shapiro, S. L., Carlson, L. E., Astin, J. A., \& Freedman, B. (2006). Mechanisms of mindfulness. Journal of Clinical Psychology, 62, 373-386.

Smeets, R. J. E. M., Vlaeyen, J. W. S., Kester, A. D. M., \& Knottnerus, J. A. (2006). Reduction of pain catastrophizing mediates the outcome of both physical and cognitive behavioral treatment in chronic low back pain. The Journal of Pain, 7, 261271.

Society of Clinical Psychology, Division 12 of the American Psychological Association. Research-supported psychological therapies. Available at: http://www.div12.org/PsychologicalTreatments/treatments/chronicpain_act.html . Accessed 24 December, 2011.

Stice, E., Rohde, P., Seely, J. R., \& Gau, J. M. (2010). Testing mediators if intervention effects in randomized controlled trials: An evaluation of three depression prevention programs. Journal of Consulting and Clinical Psychology, 78, 273-280.

Sullivan, M. J., Rouse, D., Bishop, S., \& Johnston, S. (1997). Thought suppression, 
catastrophizing, and pain. Cognitive Therapy and Research, 21, 555-568.

Thorsell, J., Finnes, A., Dahl, J., Lundgren, T., Gybrant, M., Gordh, T., \& Buhrman, M. (2011). A comparative study of 2 manual-based self-help interventions, Acceptance and Commitment Therapy and Applied Relaxation, for persons with chronic pain. Clinical Journal of Pain, 27, 716-723.

Turk, D. C. \& Burwinkle, T. M. (2005). Clinical outcomes, cost-effectiveness, and the role of psychology in treatments for chronic pain sufferers. Professional Psychology: Research and Practice, 36, 602-610.

Turk, D. C., Meichenbaum, D., \& Genest, M. (1983). Pain and behavioral medicine: A cognitive-behavioral perspective. New York: The Guilford Press.

Veehof, M. M., Oskam, M. J., Schreurs, K. M. G., \& Bohlmeijer, E. T. (2011). Acceptancebased interventions for the treatment of chronic pain: a systematic review and metaanalysis. Pain, 152, 533-542.

Vilardaga, R., Hayes, S. C., Levin, M. E., \& Muto, T. (2009). Creating strategy for progress: A contextual behavioral science approach. The Behavior Analyst, 32, 105-133.

Vowles, K. E. \& McCracken, L. M. (2008). Acceptance and values-based action in chronic pain: A study of treatment effectiveness and process. Journal of Consulting and Clinical Psychology, 76, 497-407.

Vowles, K. E., \& McCracken, L. M. (2010). Comparing the role of psychological flexibility and traditional pain mangement coping strategies in chronic pain treatment outcomes. Behaviour Research and Therapy, 48, 141-146.

Vowles, K. E., McCracken, L. M., \& Zhao-O’Brien, J. (2011). Acceptance and values-based action in chronic pain: A three year follow-up analysis of treatment effectiveness and process. Behaviour Research and Therapy, 49, 748-755. 
Vowles, K. E., Wetherell, J. L., \& Sorrell, J. T. (2009). Targeting acceptance, indfulness, and values-based action in chronic pain: Findings of two preliminary trials of an outpatient group-based intervention. Cognitive and Behavioral Practice, 16, 49-58.

Waller, G. (2009). Evidence-based treatment and therapist drift. Behaviour Research and Therapy, 47, 119-127.

Wetherell, J. L., Afari, N., Rutledge, T., Sorrell, J. T., Stoddard, J. A., Petkus, A. J., Solomon, B. C., Lehman, D. H., Liu, L., Lang, A. J., \& Atkinson, J. H. (2011). A randomized, controlled trial of acceptance and commitment therapy and cognitive-behavioral therapy for chronic pain. Pain, 152, 2098-2107.

Wicksell, R. K., Ahlqvist, J., Bring, A., Melin, L., \& Olsson, G. (2008). Can exposure and acceptance strategies improve functioning and life satisfaction in people with chronic pain and whiplash-associated disorders (WAD)? A randomized controlled trial. Cognitive Behaviour Therapy, 37, 169-182.

Wicksell, R. K., Olsson, G. L., \& Hayes, S. C. (2010). Psychological flexibility as a mediator of improvement in Acceptance and Commitment Therapy for patients with chronic pain following whiplash. European Journal of Pain, 14, 1059.e1-1059.e11.

Woby, S. R., Watson, P. J., Roach, N. K., Urmstrom, M. (2004). Are changes in fearavoidance beliefs, catastrophizing, and appraisals of control, predictive of changes in chronic low back pain and disability? European Journal of Pain, 8, 201-210.

Wood, J. V., Perunovic, E. W. Q., \& Lee, W. M. (2009). Positive self-statements: Power for some peril for others. Psychological Science, 20, 860-866. 